\title{
The First Year of Life
}

H B VALMAN

\section{CONVULSIONS IN THE OLDER INFANT}
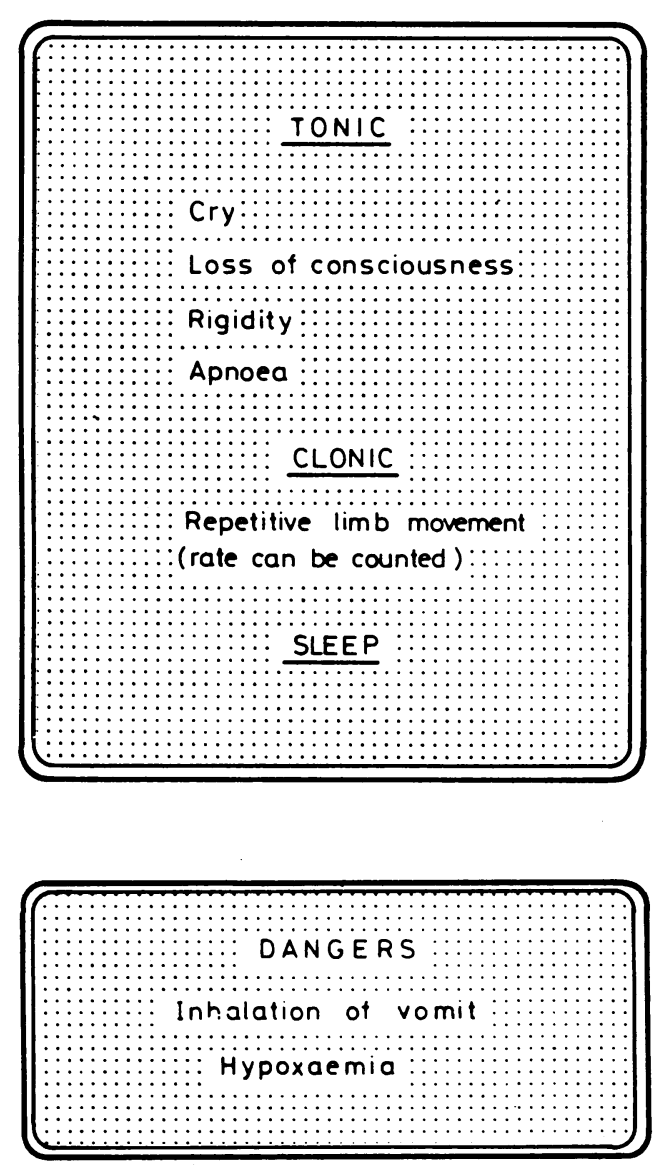

\section{Differential diagnosis}

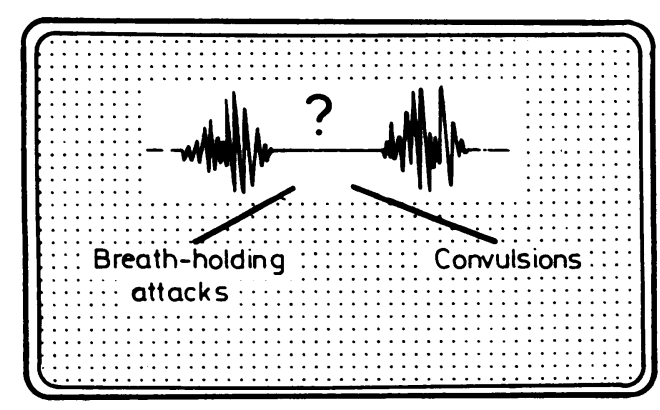

In older children the typical stages of a major convulsive attack are more easily recognised than in the newborn. There may be a frightened cry followed by abrupt loss of consciousness and muscular rigidity, which form the tonic stage. Cessation of respiratory movements and incontinence of urine and faeces may occur during this stage, which usually lasts up to half a minute. The clonic stage consists of repetitive movements of the limbs or head; these may continue for a few minutes or several hours. Inhalation of vomit is a constant danger at this time.

A period of drowsiness or sleep then occurs, which lasts from 15 minutes to several hours. Usually the child appears completely normal when he wakes but rarely there may be a hemiparesis which resolves completely during the subsequent day (Todd's paralysis). In many children, especially the younger ones, this distinctive pattern is absent and there may be simply a history of transient loss of consciousness without warning.

Although a typical major attack is easily recognised, other forms of fits may be difficult to diagnose from the mother's history. In infantile spasms the head may suddenly drop forward or the whole infant may move momentarily like a frog. In minor motor attacks the infant may suddenly have a blank appearance or carry out some stereotyped activity for a few seconds.

The possibility of fits should be considered in any infant who has repetitive attacks of changes in level of consciousness or involuntary limb movements.
Convulsions must be differentiated from breath-holding attacks, which usually begin at 9 to 18 months. Immediately after a frustrating or painful experience the infant cries vigorously and suddenly holds his breath, becomes cyanosed, and in the most severe cases loses consciousness. Rarely his limbs become rigid, and there may be a few clonic movements lasting a few seconds. Respiratory movements begin again and the infant gains consciousness immediately. The attacks diminish with age with no specific treatment. Mothers may be helped to manage these extremely frightening episodes by being told that the child will not die and that they should handle each attack consistently by putting the child on his side.

In children aged 6 months to 5 years convulsions are usually accompanied by fever. The cause of the convulsion may be an associated viraemia, the effect of a high temperature on the brain, or a vagus-mediated momentary cardiac arrest (vagal attack). 


\section{Emergency treatment}
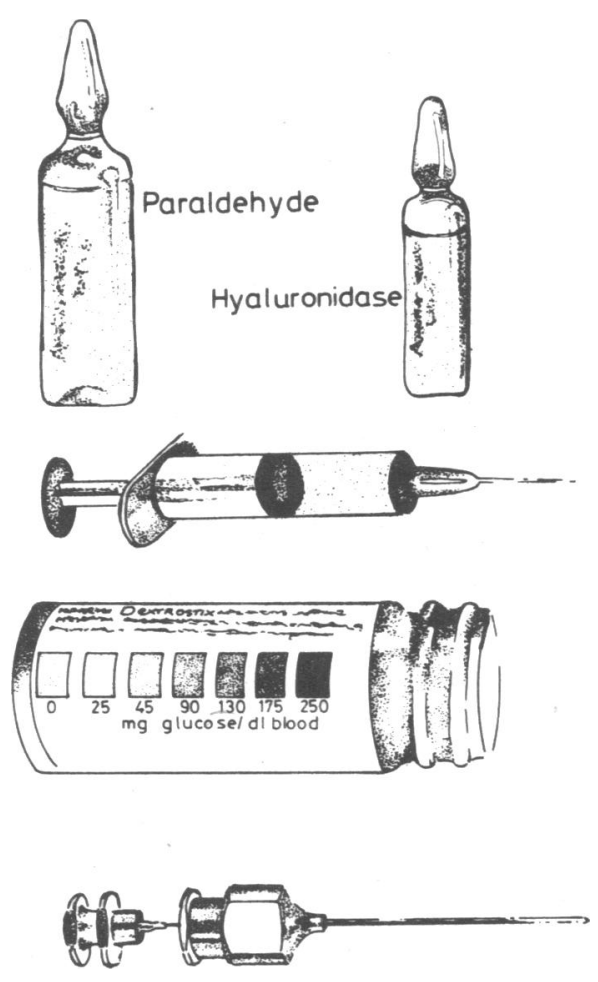

\section{Long-term management}

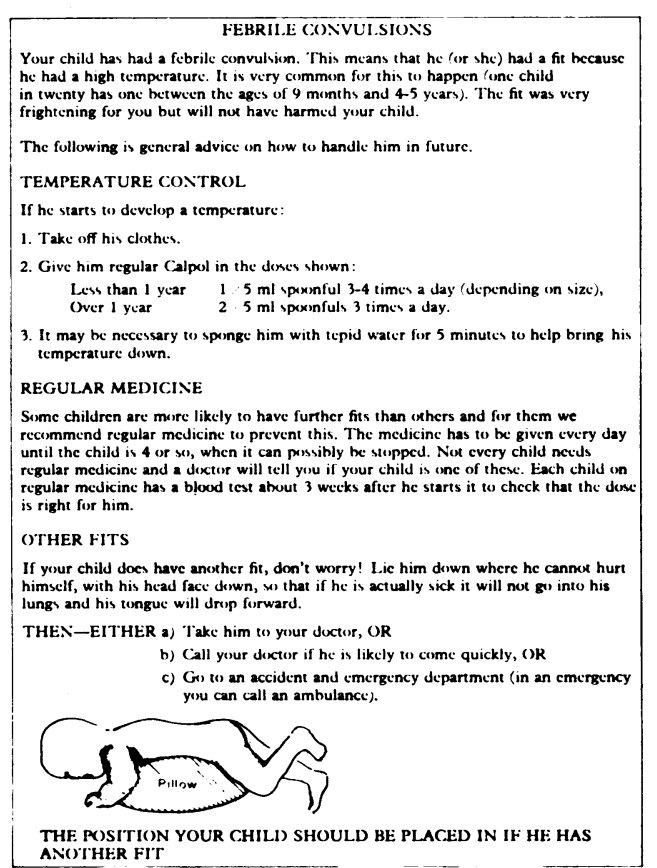
THE POSITION YOUR CHILD) SHOULD BE PLACED IN IF HE HAS
If the infant is feverish all his clothes should be removed and he should be covered with a sheet only. If his temperature does not fall within a few minutes he can be sponged with cool water or a wet sheet can be applied to his trunk. He should be nursed prone with his head to one side because vomiting with aspiration is a constant hazard.

If convulsions are still occurring or start again paraldehyde with hyaluronidase should be given intramuscularly. A glass syringe is ideal, but if only a plastic syringe is available the paraldehyde should be injected within 2 minutes of filling the syringe. The dose of paraldehyde is $0.15 \mathrm{ml} / \mathrm{kg}$. One $\mathrm{ml}$ of sterile water is added to one phial of hyaluronidase, and $0.1 \mathrm{ml}$ of this solution is aspirated into the syringe containing the measured amount of paraldehyde, which is shaken well just before injection. If the dose of paraldehyde is over $2 \mathrm{ml}$ it should be given into two sites.

The infant should then be transferred to hospital. If the convulsions do not stop within 20 minutes of giving paraldehyde, the duty anaesthetist should be present while another drug is given intravenously. Diazepam or a short-acting barbiturate must be given slowly over several minutes. Diazepam is an extremely effective anticonvulsant but it cannot be diluted and it is difficult to measure accurately the small dose needed in infants. If the dose is too large or is given too quickly, particularly if the patient has previously received an anticonvulsant, there is a risk of respiratory arrest. Early transfer to the intensive care unit should be considered if a second dose of anticonvulsant is needed.

Rectal diazepam $(0.2 \mathrm{mg} / \mathrm{kg})$ is a safe alternative to paraldehyde and produces an effective blood concentration within 10 minutes. If they have a supply of ampoules, disposable syringes, and short pieces of plastic tubing parents can give the drug themselves.

A Dextrostix test should be carried out irrespective of age. In the newborn hypoglycaemia is represented by a true plasma glucose concentration below $1.2 \mathrm{mmol} / \mathrm{l}$. For infants aged over 3 months it is less than $2.5 \mathrm{mmol} / 1$.

All infants who have had a recent convulsion should be admitted. Lumbar puncture is performed after the first convulsion to exclude meningitis. Physical examination usually does not show a cause for the fever. Occasionally acute otitis media is present and an antibiotic is indicated but most children with febrile convulsions do not need one.

Febrile convulsions occur in about $3 \%$ of children. Of the children with febrile convulsions, about one-third will have further attacks, but fewer than 3\% have convulsions after the age of 5 years. If they think he has fever parents are advised to cool the child by taking off his clothes and giving him paracetamol. A simple leaflet on the management of convulsions can be given to the parents.

The use of prophylactic anticonvulsants is controversial: opinions vary from giving anticonvulsants to all or selected children who have had a febrile convulsion to giving them to none. Some children have febrile convulsions without warning or obvious fever, and some studies have suggested that prophylactic phenobarbitone can prevent recurrences. Other studies have shown no benefit from phenobarbitone. Most children receiving phenobarbitone suffer changes in their behaviour, and, in particular, they become irritable. This may be reduced by giving a single large dose at night only. Recently sodium valproate has been found to be as effective as phenobarbitone in preventing recurrences of febrile convulsions. Children who have had their first febrile convulsion before the age of 18 months are at high risk of further attacks.

Idiopathic epilepsy with major attacks is rare before the age of 5 years. Any infant who has had any form of fit before the age of 1 year should be referred to a paediatrician in an attempt to determine whether there is any cause for the convulsion and to suggest a plan of management.

Dr H B Valman, MD, FRCP, is consultant paediatrician, Northwick Park Hospital and Clinical Research Centre, Harrow. 